\title{
Patterns of heroin and cocaine injection and plasma HIV-1 RNA suppression among a long-term cohort of injection drug users
}

\author{
Thomas Kerr $^{1,2}$, Brandon D. L. Marshall ${ }^{1,3}$, M-J Milloy ${ }^{1,4}$, Ruth Zhang ${ }^{1}$, Silvia Guillemi ${ }^{1,6}$, \\ Julio S. G. Montaner ${ }^{1,2}$, and Evan Wood ${ }^{1,2}$ \\ ${ }^{1}$ British Columbia Centre for Excellence in HIV/AIDS, 608 - 1081 Burrard Street, Vancouver, \\ British Columbia V6Z 1Y6, Canada \\ ${ }^{2}$ Department of Medicine, University of British Columbia, 2775 Laurel Street, 10th Floor, \\ Vancouver, British Columbia V5Z 1M9, Canada \\ ${ }^{3}$ Department of Epidemiology, Mailman School of Public Health, Columbia University, Allan \\ Rosenfield Building, 722 West 168th Street, New York, NY 10032, USA \\ ${ }^{4}$ School of Population and Public Health, University of British Columbia, Vancouver, Canada \\ ${ }^{5}$ Provincial Health Services Authority, 700 - 1380 Burrard Street, Vancouver, British Columbia \\ V6Z 2H3, Canada \\ ${ }^{6}$ Department of Family Practice, University of British Columbia, David Strangway Building, 3rd \\ Floor, 5950 University Boulevard, Vancouver, British Columbia V6T 1Z3, Canada
}

\section{Abstract}

\begin{abstract}
Background-Previous studies suggest that active drug use may compromise HIV treatment among HIV-positive injection drug users (IDU). However, little is known about the differential impacts of cocaine injection, heroin injection, and combined cocaine and heroin injection on plasma HIV-1 RNA suppression.
\end{abstract}

Methods-Data were derived from a longstanding open prospective cohort of HIV-positive IDU in Vancouver, Canada. Kaplan-Meier methods and Cox proportional hazards regression were used to examine the impacts of different drug use patterns on rates of plasma HIV-1 RNA suppression.

(C) 2011 Elsevier Ireland Ltd. All rights reserved.

Send correspondence to: Dr. Thomas Kerr, British Columbia Centre for Excellence in HIV/AIDS, 608 - 1081 Burrard Street, Vancouver, British Columbia V6Z 1Y6, Canada, Phone: 604806 9116, Fax: 604806 9044, uhri-ew@cfenet.ubc.ca.

Contributors

E. Wood had full access to all of the data in the study and takes full responsibility for the integrity of the data and the accuracy of the data analysis. T. Kerr, B. Marshall, and E. Wood designed the study and wrote the protocol. R. Zhang conducted the statistical analysis, and all authors interpreted the results. T. Kerr wrote the manuscript. E. Wood, B. Marshall, M-J Milloy, S. Guillemi, and J. Montaner critically revised the manuscript and contributed important intellectual content. All authors have read and approved the final version of the manuscript.

\section{Conflict of Interest}

J. Montaner has received educational grants from, has served as an ad hoc advisor to, or has spoken at various events sponsored by Abbott Laboratories, Agouron Pharmaceuticals Inc., Boehringer Ingelheim Pharmaceuticals Inc., Borean Pharma AS, Bristol-Myers Squibb, DuPont Pharma, Gilead Sciences, GlaxoSmithKline, Hoffmann-La Roche, Immune Response Corporation, Incyte, JanssenOrtho Inc., Kucera Pharmaceutical Company, Merck Frosst Laboratories, Pfizer Canada Inc., Sanofi Pasteur, Shire Biochem Inc., Tibotec Pharmaceuticals Ltd., and Trimeris Inc. All other authors declare that they have no conflicts of interest.

Publisher's Disclaimer: This is a PDF file of an unedited manuscript that has been accepted for publication. As a service to our customers we are providing this early version of the manuscript. The manuscript will undergo copyediting, typesetting, and review of the resulting proof before it is published in its final citable form. Please note that during the production process errors may be discovered which could affect the content, and all legal disclaimers that apply to the journal pertain. 
Results-Between May 1996 and April 2008, 267 antiretroviral (ART) naïve participants were seen for a median follow-up duration of 50.6 months after initiating ART. The incidence density of HIV-1 RNA suppression was 65.2 (95\%CI: 57.0-74.2) per 100 person-years. In Kaplan-Meier analyses, compared to those who abstained from injecting, individuals injecting heroin, cocaine, or combined heroin/cocaine at baseline were significantly less likely to achieve viral suppression (all $p<0.01$ ). However, none of the drug use categories remained associated with a reduced rate of viral suppression when considered as time-updated variables (all $p>0.05$ ).

Conclusions-Active injecting at the time of ART initiation was associated with lower plasma HIV-1 RNA suppression rates; however, there was no difference in suppression rates when drug use patterns were examined over time. These findings imply that adherence interventions for active injectors should optimally be applied at the time of ART initiation.

\section{Keywords}

injection drug use; antiretroviral therapy; viral suppression

\section{Introduction}

Injection drug users (IDU) continue to account for a substantial proportion of new HIV infections globally, and in some areas with rapidly growing epidemics of HIV infection, IDU account for the majority of new infections (UNAIDS, 2008). While recent medical advances in the treatment of HIV disease have resulted in substantial reductions in AIDSrelated morbidity and mortality (Egger et al., 2002; Hammer et al., 1997; Wood et al., 2003), a growing body of evidence indicates that not all populations affected by HIV disease have benefited equally from available treatments (Aceijas et al., 2006; Chander et al., 2006; Poundstone et al., 2001). For example, IDU experience many barriers to accessing highly active antiretroviral therapy (ART) and suffer from low rates of adherence once initiated (Aceijas et al., 2006; Mocroft et al., 1999; Wood et al., 2003b); as a consequence, this population often has poorer AIDS-related outcomes (Egger et al., 2002; Lucas et al., 2001; Palepu et al., 2003).

Ongoing illicit drug use among HIV-positive IDU remains a common clinical presentation that raises significant concerns for healthcare providers considering when to initiate ART (Ding et al., 2005; Loughlin et al., 2004; Maisels et al., 2001). This is due in part to a body of evidence indicating that active drug use is associated with lower rates of adherence to ART and suppression of HIV RNA (Arnsten et al., 2002; Egger et al., 2002; Lucas et al., 1999; Lucas et al., 2001; Palepu et al., 2003; Weber et al., 2009). However, while negative impacts of active drug use on HIV-related clinical outcomes have been shown in several studies, little is known about the relationship between specific drugs and patterns of use on outcomes associated with HIV disease (Krüsi et al., 2010). A small number of studies have revealed adverse effects of crack cocaine use (Moss et al., 2004; Sullivan et al., 2007) (Baum et al., 2009) and stimulant use more generally (Hinkin et al., 2007; Kapadia et al., 2005) on adherence and progression to AIDS. However, we know of no longitudinal studies that have sought to compare the distinct effects of different drugs on outcomes associated with the treatment of HIV disease, despite recent calls for this type of research (Krüsi et al., 2010). In addition, questions remain concerning the relative contributions of other behavioral factors to poor clinical outcomes among IDU (Krüsi et al., 2010; Wood et al., 2008).

Vancouver, Canada, is home to a large injection-drug-related HIV epidemic that is unique because of the widespread availability of several different types of illegal drugs, including injection cocaine and heroin (Wood and Kerr, 2006). This unique context and the presence of a large, longstanding prospective cohort study of HIV-positive IDU conducted within a 
context of universal access to free healthcare afforded the opportunity to examine the impact of different types of illicit drug use on suppression of HIV-1 RNA.

\section{Methods}

The AIDS Care Cohort to Evaluate Exposure to Survival Services (ACCESS) is a prospective observational cohort of HIV-seropositive injection drug users in Vancouver, Canada. The cohort has been described in detail previously (Wood et al., 2008) and was populated through snowball sampling and extensive street outreach methods in the city's Downtown Eastside. Individuals were eligible for ACCESS if they were aged 18 years or older, HIV-seropositive, had used injection drugs at least once in the previous six months, and provided written informed consent. At baseline and semi-annually, participants answered a standardized interviewer-administered questionnaire and provided blood samples for serologic analysis.

As previously described (Strathdee et al., 1998; Wood et al., 2004; Wood et al., 2008), the local setting is perhaps unique in that there is a universal healthcare system and a provincewide centralized antiretroviral dispensation program and HIV/AIDS laboratory which enables a complete prospective profile of all patient CD4 cell count determinations and plasma HIV-1 RNA levels, as well as a complete prospective profile of antiretroviral therapy use among cohort participants. This includes the specific antiretroviral agents and the prescribed dose, as well as a validated measure of patient adherence derived from prescription refill compliance (Wood et al., 2008; Wood et al., 2003a). The guidelines for the initiation of ART evolved during the study period in accordance with the guidelines set by the International AIDS Society-USA Panel (Carpenter et al., 1998; Hammer et al., 2006). The study has been approved by the Providence Health Care/University of British Columbia Research Ethics Board.

In the present study, because updated laboratory data were available throughout the study period, we were able to consider all participants who completed at least one interview between May 1996 and April 2008, were antiretroviral-naïve at baseline, and initiated treatment at any point during follow-up. Viral load suppression was defined as the first instance of achieving plasma HIV-1 RNA suppression of less than 500 copies $/ \mathrm{mL}$. The key independent variables of interest were: exclusive cocaine injection (yes vs. no); exclusive heroin injection (yes vs. no); and heroin and cocaine injection in combination (yes vs. no). Individuals injecting cocaine, heroin, or heroin and cocaine in combination at least once in the previous six months were included in these categories. For each of these variables, the reference category was no injection drug use (i.e., individuals who did not report any injecting in the previous six months).

Additional independent variables of interest included: age (per 10 years older); current methadone use (yes vs. no); baseline CD4 cell count (cells $/ \mu \mathrm{L}$, per 100-cell increase); baseline plasma HIV-1 RNA (per $\log _{10}$ increase); protease inhibitor (PI) use at ART initiation (yes vs. other regimen); year of ART initiation (per year later); and ART adherence ( $\geq$ vs. $<95 \%$ adherence). All variable definitions were identical to earlier reports (Uhlmann et al., 2010; Wood et al., 2008). Unless otherwise noted, all behavioral data refer to the six-month period prior to the follow-up interview. Plasma HIV-1 RNA was measured using the Roche Amplicor Monitor assay (Roche Molecular Systems, Mississauga, Canada).

As an initial step, we compared selected demographic (age, gender, Aboriginal ancestry) and clinical (methadone treatment use, HIV-1 viral load, CD4 cell count) characteristics among those who did and did not report injecting at baseline. To test for significant differences among these groups we used the Pearson's Chi-square test and the Wilcoxon rank sum test. Cumulative HIV-1 RNA suppression rates were then estimated using Kaplan-Meier 
methods. Here we compared HIV-1 RNA suppression rates among individuals reporting no injection drug use, exclusive cocaine injecting, exclusive heroin injecting, combined heroin/ cocaine injecting, and injecting of drugs other than heroin and cocaine. Survival curves were compared using the log-rank test. Time zero was defined as the date of ART initiation. Participants who consistently remained unsuppressed were right-censored at the time of their most recent HIV-1 RNA plasma measurement.

We were interested in comparing the effects of the different drugs (heroin and cocaine either alone or in combination) on suppression and what the effect was when these drugs were injected after ART was initiated. We were also interested to discern the independent effect of drug use patterns after adjusting for clinical and behavioral characteristics. To achieve this, univariate and multivariate Cox regression was used to assess the independent effects of different types of drug use during follow-up on HIV-1 RNA suppression rates.

In total, three statistical models were constructed. Each model considered each drug use behavior as a time-updated variable (measuring drug use in the previous six months throughout follow-up). Considering drug use as a time-updated behavior meant that participants could move from injecting to non-injecting, or from one drug use pattern (e.g., heroin injecting) to another drug use pattern (e.g., combined heroin and cocaine injecting) during study follow-up. In the first model, we estimated the unadjusted association between HIV-1 RNA suppression and each drug use variable of interest. In a second fixed multivariate Cox model, we estimated the association between each drug use variable and HIV-1 RNA suppression, after adjustment for baseline CD4 cell count and baseline plasma HIV-1 RNA level. In a third confounding model, we estimated the association between each drug use variable and HIV-1 RNA suppression, after adjustment for baseline CD4 cell count, baseline plasma HIV-1 RNA load, age, methadone use, 95\% adherence, year of ART initiation, and regimen (PI or other) used for initial HAART regimen. To fit the multivariate confounding model, we employed a conservative backward selection approach. Beginning with a full model with all covariates included, secondary explanatory variables were dropped one at a time, using the relative change in the regression coefficient for the variable related to drug use as a criterion, until the smallest relative change in the coefficient for the drug use variable exceeded 5\%. We then fitted the final model, including the drug use variable of interest and all remaining secondary explanatory variables as terms in the regression equation. All tests of significance were two-sided, with a $p$-value of less than 0.05 indicating that an association was statistically significant. All statistical analyses were performed using SAS software (SAS, Cary, NC).

\section{Results}

Among these 267 participants, 124 (46.4\%) were female, 105 (39.3\%) were of Aboriginal ancestry, and the median age at baseline was 36.5 years (interquartile range $[\mathrm{IQR}]=29.8$ 43.5). The median duration of follow-up was 50.6 (IQR $=16.5-95.0)$ months. The median CD4 cell count at baseline was 240 (IQR $=140-360$ ) cells $/ \mu \mathrm{L}$, while the median HIV-1 viral load was 86,000 (IQR $=36,300-120,000)$ copies $/ \mathrm{ml}$. The cumulative rate of HIV-1 RNA suppression for the entire sample was 65.2 (95\% confidence interval [CI]: 57.0-74.2) per 100 person-years. As indicated in Table 1, $230(86.1 \%)$ participants reported injecting at baseline, while 37 (13.9\%) reported no injecting. A comparison of participants who did and did not report injecting at baseline revealed no significant differences between the groups with respect to any of the socio-demographic or clinical characteristics considered (all $p$ > 0.05 ), with the exception that those who did not report injecting at baseline had a lower median HIV-1 viral load than those who did report injecting (61,000 copies/ml vs. 90,500 copies/ml, $p=0.032$ ). 
The Kaplan-Meier analysis of the cumulative plasma HIV-1 RNA suppression rate stratified by baseline drug use is shown in Figure 1. As shown here, at 12 months, the cumulative HIV-1 suppression rate was not statistically different for those injecting cocaine, heroin, or cocaine and heroin in combination (all log-rank: $p>0.05$ ), with the rate of HIV-1 RNA suppression at 12 months being 55.5\% (95\% CI: 44.6\%-67.0\%) for cocaine injectors, $57.6 \%$ (95\%CI: $40.6 \%-75.6 \%$ ) for heroin injectors, and $55.9 \%$ (95\%CI: $47.1 \%-65.1 \%$ ) for IDU injecting heroin and cocaine in combination. The rate of HIV-1 RNA suppression for noninjectors at 12 months was $88.8 \%$ (95\%CI: $76.2 \%-96.4 \%)$. There were statistically detectable differences in the rates of HIV-1 RNA suppression between the non-injecting group and each of the three drug injecting groups (all pairwise log-rank: $p<0.01$ ).

The results of the Cox regression analyses examining the associations between the various drug use variables and HIV-1 RNA suppression are shown in Figure 2. As shown here, when the drug use variables were considered as time-updated variables in Model 1, only the unadjusted association between combined cocaine/heroin injection and HIV-1 RNA suppression (hazard ratio $[\mathrm{HR}]=0.67,95 \% \mathrm{CI}$ : 0.47-0.97) was statistically significant. In Model 2, none of the drug use variables remained significantly associated with HIV-1 RNA suppression (all $p<0.05$ ) after adjustment for baseline CD4 cell count (adjusted hazard ratio [AHR] $=0.96,95 \%$ CI: 0.89-1.03), baseline plasma HIV-1 RNA viral load (AHR $=0.75$, 95\%CI: 0.60-0.94), and year of ART initiation (AHR $=1.15$, 95\%CI: $1.10-1.20)$. In Model 3 , a confounding model, none of the drug use variables remained associated with suppression of HIV-1 RNA after adjustment for baseline CD4 cell count $(\mathrm{AHR}=0.95$, 95\%CI: 0.88-1.02), baseline plasma HIV-1 RNA viral load (AHR $=0.61,95 \%$ CI: 0.49 $0.77)$, methadone use $(\mathrm{AHR}=1.33,95 \% \mathrm{CI}: 1.01-1.76), 95 \%$ adherence $(\mathrm{AHR}=4.00$, 95\%CI: 2.91-5.49), PI use (AHR = 1.35, 95\%CI: 1.03-1.77), and year of ART initiation $(\mathrm{AHR}=1.10,95 \% \mathrm{CI}: 1.05-1.15)$.

\section{Discussion}

The present study demonstrates lower rates of plasma HIV-1 RNA suppression among IDU who are actively injecting at the time of ART initiation in comparison to individuals who were not injecting at this time. The effects of the various drugs (e.g., heroin vs. cocaine) on HIV-1 RNA viral suppression did not differ greatly when baseline drug use was considered. When injection drug use patterns throughout follow-up were considered in time-updated models, differences between abstinent and active injection drug use categories diminished. Suppression of HIV-1 RNA was most strongly predicted by baseline clinical characteristics (e.g., baseline plasma HIV-1 RNA viral load), use of methadone, and adherence to ART.

While the comparison of baseline drug use patterns is consistent with past work (Arnsten et al., 2002; Egger et al., 2002; Lucas et al., 1999; Lucas et al., 2001; Palepu et al., 2003; Weber et al., 2009), our comparison of longitudinal drug use patterns stands in contrast to previous work indicating that active drug use is associated with poorer clinical outcomes (Arnsten et al., 2002; Poundstone et al., 2001). This may be because of differences in the length of follow-up time, sample sizes, and the measurement of drug use behavior across studies (Baum et al., 2009; Hinkin et al., 2007; Krüsi et al., 2010). To date, only a limited number of studies have examined the impact of ongoing drug use longitudinally, and only a few studies have examined the impacts of time-updated drug use behaviors on viral suppression (Arnsten et al., 2002; Lucas et al., 2001; Lucas et al., 2006). The finding that active drug use, when measured as a time-updated behavior, did not predict suppression of HIV-1 RNA after multivariate adjustment may also reflect the natural history of injection drug use, which is typically characterized by periods of varying intensity of injecting as well as periods of no injecting, rather than trajectories marked by constant levels of injecting that are fixed at baseline (Bruneau et al., 2004; Galai et al., 2003). These findings may also be 
explained by: evolving characteristics of the local healthcare and social service systems, including housing and adherence support programs (Tyndall et al., 2007), which serve to support adherence to ART among active IDU; or the universal healthcare system, which provides ART free of charge to local IDU regardless of active drug use (Evans and Strathdee, 2006; Tyndall et al., 2007). Indeed, several previous studies examining the impact of ongoing drug use on ART-related outcomes among IDU have been conducted in the context of medical systems with significant barriers to HIV treatment, which may disproportionally affect IDU (Arnsten et al., 2002; Lucas et al., 1999; Poundstone et al., 2001). Regardless, taken together, these findings imply that adherence interventions should be optimally applied at the time of ART initiation.

Of interest, IDU injecting cocaine, heroin, and heroin and cocaine in combination had similar rates of HIV-1 RNA suppression. However, it is notable that individuals injecting heroin and heroin and cocaine in combination had slightly worse outcomes in comparison to those IDU who injected cocaine exclusively. There have been concerns that stimulant injection could have a particularly destabilizing effect on ART adherence and associated clinical outcomes because of the frequency of injections and the short half-life of cocaine, as well as the psychological sequelae and chaotic behavior that may stem from its use and the lack of an appropriate substitution therapy, as in the case of heroin (Arnsten et al., 2002; Hinkin et al., 2007). While previous research has found active cocaine use to be associated with suboptimal adherence and suboptimal virological response (Arnsten et al., 2002; Berg et al., 2004; Hinkin et al., 2007), the present study suggests that opioid injectors may have equally poor, if not worse, outcomes.

This study has limitations. Our sample was not randomly selected and therefore may not be fully representative of the larger population of treatment-eligible HIV-positive individuals with a history of injection drug use in our setting. Additionally, because of socially desirable reporting, IDU in our study may have underreported recent drug use (Des Jarlais et al., 1999), which could have resulted in a possible underestimation of the influence of ongoing drug use on suppression of HIV-1 RNA. This is a hypothetical concern, however, and it is noteworthy that self-reported abstinence at baseline was strongly associated with higher rates of HIV RNA-1 suppression. Further, we may have failed to measure more direct biological mechanisms or processes with potential to mediate the relationship between drug use and suppression of HIV-1 RNA. Finally, while initial response to ART predicts longterm outcomes (Sterne et al., 2005) and it is conventional for clinical trials to look at initial virological responses, our study did not assess long-term outcomes from ART. It is possible that relapses into injecting drug use, while not having an obvious effect on initial ART response, may in fact have impacts on longer-term outcomes.

In summary, active drug injecting at the time of ART initiation is associated with lower plasma HIV-1 RNA suppression rates. Interestingly, when considered longitudinally as time-updated behaviors, there was little association between patterns of drug injecting and plasma HIV-1 RNA suppression rates. These findings imply that adherence interventions should be applied at the time of ART initiation for active drug injectors.

\section{Acknowledgments}

Role of Funding Source

This study was supported by US National Institutes of Health (NIH) grant R01DA021525 and Canadian Institutes of Health Research (CIHR) grants MOP-79297 and RAA-79918. T. Kerr is supported by awards from the Michael Smith Foundation for Health Research (MSFHR) and CIHR. M-J Milloy is supported by awards from CIHR and MSFHR. B. Marshall is supported by a research fellowship award from CIHR and an International AIDS Society/ National Institute on Drug Abuse (NIDA) Fellowship in Encouraging HIV and Drug Use Research. J. Montaner is supported by a NIDA Avant-Garde award. None of the funders had any further role in study design; in the 
collection, analysis or interpretation of data; in the writing of the report; or in the decision to submit the paper for publication.

The authors sincerely thank the study participants for their contribution to the research, as well as current and past researchers and staff. We would specifically like to thank Deborah Graham, Tricia Collingham, Caitlin Johnston, Steve Kain, and Calvin Lai for their research and administrative assistance.

\section{References}

Aceijas C, Oppenheimer E, Stimson GV, Ashcroft RE, Matic S, Hickman M. Antiretroviral treatment for injecting drug users in developing and transitional countries 1 year before the end of the "Treating 3 million by 2005. Making it happen. The WHO strategy" (“3 by 5"). Addiction. 2006; 101:1246-1253. [PubMed: 16911723]

Arnsten JH, Demas PA, Grant RW, Gourevitch MN, Farzadegan H, Howard AA, Schoenbaum EE. Impact of active drug use on antiretroviral therapy adherence and viral suppression in HIV-infected drug users. J Gen Intern Med. 2002; 17:377-381. [PubMed: 12047736]

Baum MK, Rafie C, Lai S, Sales S, Page B, Campa A. Crack-cocaine use accelerates HIV disease progression in a cohort of HIV-positive drug users. J Acquir Immune Defic Syndr. 2009; 50:93-99. [PubMed: 19295339]

Berg KM, Demas PA, Howard AA, Schoenbaum EE, Gourevitch MN, Arnsten JH. Gender differences in factors associated with adherence to antiretroviral therapy. J Gen Intern Med. 2004; 19:11111117. [PubMed: 15566440]

Bruneau J, Brogly SB, Tyndall MW, Lamothe F, Franco EL. Intensity of drug injection as a determinant of sustained injection cessation among chronic drug users: the interface with social factors and service utilization. Addiction. 2004; 99:727-737. [PubMed: 15139871]

Carpenter CC, Fischl MA, Hammer SM, Hirsch MS, Jacobsen DM, Katzenstein DA, Montaner JS, Richman DD, Saag MS, Schooley RT, Thompson MA, Vella S, Yeni PG, Volberding PA. Antiretroviral therapy for HIV infection in 1998: updated recommendations of the International AIDS Society-USA Panel. JAMA. 1998; 280:78-86. [PubMed: 9660368]

Chander G, Himelhoch S, Moore RD. Substance abuse and psychiatric disorders in HIV-positive patients: epidemiology and impact on antiretroviral therapy. Drugs. 2006; 66:769-789. [PubMed: 16706551]

Des Jarlais DC, Paone D, Milliken J, Turner CF, Miller H, Gribble J, Shi Q, Hagan H, Friedman SR. Audio-computer interviewing to measure risk behaviour for HIV among injecting drug users: a quasi-randomised trial. Lancet. 1999; 353:1657-1661. [PubMed: 10335785]

Ding L, Landon BE, Wilson IB, Wong MD, Shapiro MF, Cleary PD. Predictors and consequences of negative physician attitudes toward HIV-infected injection drug users. Arch Intern Med. 2005; 165:618-623. [PubMed: 15795336]

Egger M, May M, Chene G, Phillips AN, Ledergerber B, Dabis F, Costagliola D, D'Arminio Monforte A, de Wolf F, Reiss P, Lundgren JD, Justice AC, Staszewski S, Leport C, Hogg RS, Sabin CA, Gill MJ, Salzberger B, Sterne JA. Prognosis of HIV-1-infected patients starting highly active antiretroviral therapy: a collaborative analysis of prospective studies. Lancet. 2002; 360:119-129. [PubMed: 12126821]

Evans L, Strathdee SA. A roof is not enough: unstable housing, vulnerability to HIV infection and the plight of the SRO. Int J Drug Pol. 2006; 17:115-117.

Galai N, Safaeian M, Vlahov D, Bolotin A, Celentano DD. Longitudinal patterns of drug injection behavior in the ALIVE Study cohort, 1988-2000: description and determinants. Am J Epidemiol. 2003; 158:695-704. [PubMed: 14507606]

Hammer SM, Saag MS, Schechter M, Montaner JS, Schooley RT, Jacobsen DM, Thompson MA, Carpenter CC, Fischl MA, Gazzard BG, Gatell JM, Hirsch MS, Katzenstein DA, Richman DD, Vella S, Yeni PG, Volberding PA. Treatment for adult HIV infection: 2006 recommendations of the International AIDS Society-USA panel. JAMA. 2006; 296:827-843. [PubMed: 16905788]

Hammer SM, Squires KE, Hughes MD, Grimes JM, Demeter LM, Currier JS, Eron JJ Jr, Feinberg JE, Balfour HH Jr, Deyton LR, Chodakewitz JA, Fischl MA. A controlled trial of two nucleoside analogues plus indinavir in persons with human immunodeficiency virus infection and CD4 cell

Drug Alcohol Depend. Author manuscript; available in PMC 2013 July 01. 
counts of 200 per cubic millimeter or less. AIDS Clinical Trials Group 320 Study Team. N Engl J Med. 1997; 337:725-733. [PubMed: 9287227]

Hinkin CH, Barclay TR, Castellon SA, Levine AJ, Durvasula RS, Marion SD, Myers HF, Longshore D. Drug use and medication adherence among HIV-1 infected individuals. AIDS Behav. 2007; 11:185-194. [PubMed: 16897351]

Kapadia F, Cook JA, Cohen MH, Sohler N, Kovacs A, Greenblatt RM, Choudhary I, Vlahov D. The relationship between non-injection drug use behaviors on progression to AIDS and death in a cohort of HIV seropositive women in the era of highly active antiretroviral therapy use. Addiction. 2005; 100:990-1002. [PubMed: 15955015]

Krüsi A, Milloy MJ, Kerr T, Zhang R, Guillemi S, Hogg R, Montaner JS, Wood E. Ongoing drug use and outcomes from highly active antiretroviral therapy among injection drug users in a Canadian setting. Antivir Ther. 2010; 15:789-96. [PubMed: 20710061]

Loughlin A, Metsch L, Gardner L, Anderson-Mahoney P, Barrigan M, Strathdee S. Provider barriers to prescribing HAART to medically-eligible HIV-infected drug users. AIDS Care. 2004; 16:485500. [PubMed: 15203416]

Lucas GM, Chaisson RE, Moore RD. Highly active antiretroviral therapy in a large urban clinic: risk factors for virologic failure and adverse drug reactions. Ann Intern Med. 1999; 131:81-87. [PubMed: 10419445]

Lucas GM, Cheever LW, Chaisson RE, Moore RD. Detrimental effects of continued illicit drug use on the treatment of HIV-1 infection. J Acquir Immune Defic Syndr. 2001; 27:251-259. [PubMed: $11464144]$

Lucas GM, Griswold M, Gebo KA, Keruly J, Chaisson RE, Moore RD. Illicit drug use and HIV-1 disease progression: a longitudinal study in the era of highly active antiretroviral therapy. Am $\mathrm{J}$ Epidemiol. 2006; 163:412-420. [PubMed: 16394200]

Maisels L, Steinberg J, Tobias C. An investigation of why eligible patients do not receive HAART. AIDS Patient Care STDS. 2001; 15:185-191. [PubMed: 11359660]

Mocroft A, Madge S, Johnson AM, Lazzarin A, Clumeck N, Goebel FD, Viard JP, Gatell J, Blaxhult A, Lundgren JD. A comparison of exposure groups in the EuroSIDA study: starting highly active antiretroviral therapy (HAART), response to HAART, and survival. J Acquir Immune Defic Syndr. 1999; 22:369-378. [PubMed: 10634199]

Moss AR, Hahn JA, Perry S, Charlebois ED, Guzman D, Clark RA, Bangsberg DR. Adherence to highly active antiretroviral therapy in the homeless population in San Francisco: a prospective study. Clin Infect Dis. 2004; 39:1190-1198. [PubMed: 15486844]

Palepu A, Tyndall M, Yip B, O’Shaughnessy MV, Hogg RS, Montaner JS. Impaired virologic response to highly active antiretroviral therapy associated with ongoing injection drug use. J Acquir Immune Defic Syndr. 2003; 32:522-526. [PubMed: 12679704]

Poundstone KE, Chaisson RE, Moore RD. Differences in HIV disease progression by injection drug use and by sex in the era of highly active antiretroviral therapy. AIDS. 2001; 15:1115-1123. [PubMed: 11416713]

Sterne JA, Hernan MA, Ledergerber B, Tilling K, Weber R, Sendi P, Rickenbach M, Robins JM, Egger M. Long-term effectiveness of potent antiretroviral therapy in preventing AIDS and death: a prospective cohort study. Lancet. 2005; 366:378-384. [PubMed: 16054937]

Strathdee SA, Palepu A, Cornelisse PG, Yip B, O’Shaughnessy MV, Montaner JS, Schechter MT, Hogg RS. Barriers to use of free antiretroviral therapy in injection drug users. JAMA. 1998; 280:547-549. [PubMed: 9707146]

Sullivan PS, Campsmith ML, Nakamura GV, Begley EB, Schulden J, Nakashima AK. Patient and regimen characteristics associated with self-reported nonadherence to antiretroviral therapy. PLoS ONE. 2007; 2:e552. [PubMed: 17579723]

Tyndall MW, McNally M, Lai C, Zhang R, Wood E, Kerr T, Montaner JS. Directly observed therapy programmes for anti-retroviral treatment amongst injection drug users in Vancouver: access, adherence and outcomes. Int J Drug Policy. 2007; 18:281-287. [PubMed: 17689376]

Uhlmann S, Milloy MJ, Kerr T, Zhang R, Guillemi S, Marsh D, Hogg RS, Montaner JS, Wood E. Methadone maintenance therapy promotes initiation of antiretroviral therapy among injection drug users. Addiction. 2010; 105:907-913. [PubMed: 20331553] 
UNAIDS. 2008 report on the global AIDS epidemic. UNAIDS; Geneva: 2008.

Weber R, Huber M, Rickenbach M, Furrer H, Elzi L, Hirschel B, Cavassini M, Bernasconi E, Schmid $\mathrm{P}$, Ledergerber B. Uptake of and virological response to antiretroviral therapy among HIV-infected former and current injecting drug users and persons in an opiate substitution treatment programme: the Swiss HIV Cohort Study. HIV Med. 2009; 10:407-416. [PubMed: 19490174]

Wood E, Hogg RS, Bonner S, Kerr T, Li K, Palepu A, Guillemi S, Schechter MT, Montaner JS. Staging for antiretroviral therapy among HIV-infected drug users. JAMA. 2004; 292:1175-1177. [PubMed: 15353528]

Wood E, Hogg RS, Lima VD, Kerr T, Yip B, Marshall BD, Montaner JS. Highly active antiretroviral therapy and survival in HIV-infected injection drug users. JAMA. 2008; 300:550-554. [PubMed: 18677027]

Wood E, Hogg RS, Yip B, Harrigan PR, O'Shaughnessy MV, Montaner JS. Effect of medication adherence on survival of HIV-infected adults who start highly active antiretroviral therapy when the CD4+ cell count is 0.200 to $0.350 \times 10(9)$ cells/L. Ann Intern Med. 2003a; 139:810-816. [PubMed: 14623618]

Wood E, Kerr T. What do you do when you hit rock bottom: responding to drugs in the City of Vancouver. Int J Drug Policy. 2006; 17:55-60.

Wood E, Montaner JS, Yip B, Tyndall MW, Schechter MT, O’Shaughnessy MV, Hogg RS. Adherence and plasma HIV RNA responses to highly active antiretroviral therapy among HIV-1 infected injection drug users. CMAJ. 2003b; 169:656-661. [PubMed: 14517122] 


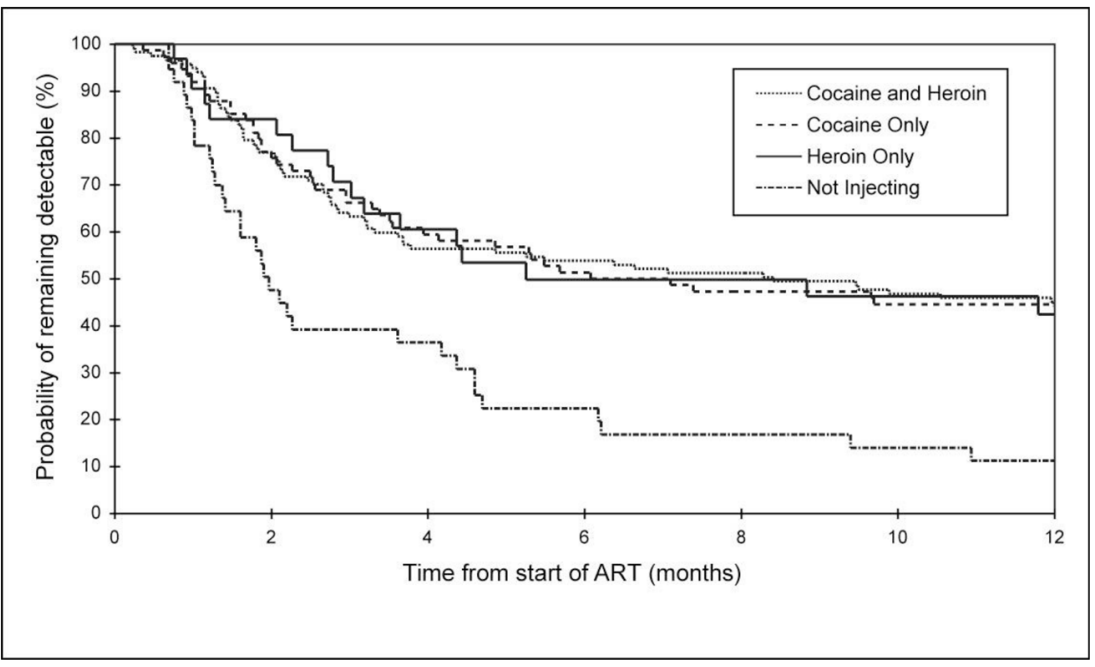

Figure 1.

Kaplan-Meier estimates of cumulative rates of plasma HIV-1 RNA suppression within a sample of 267 injection drug users who initiated highly active antiretroviral therapy (ART) during the study period. All pairwise comparisons between injecting groups were nonsignificant (log-rank: $p>0.05$ ). All pairwise comparisons between the non-injecting group and the three drug-injecting groups were significant (log-rank $p<0.01)$. 


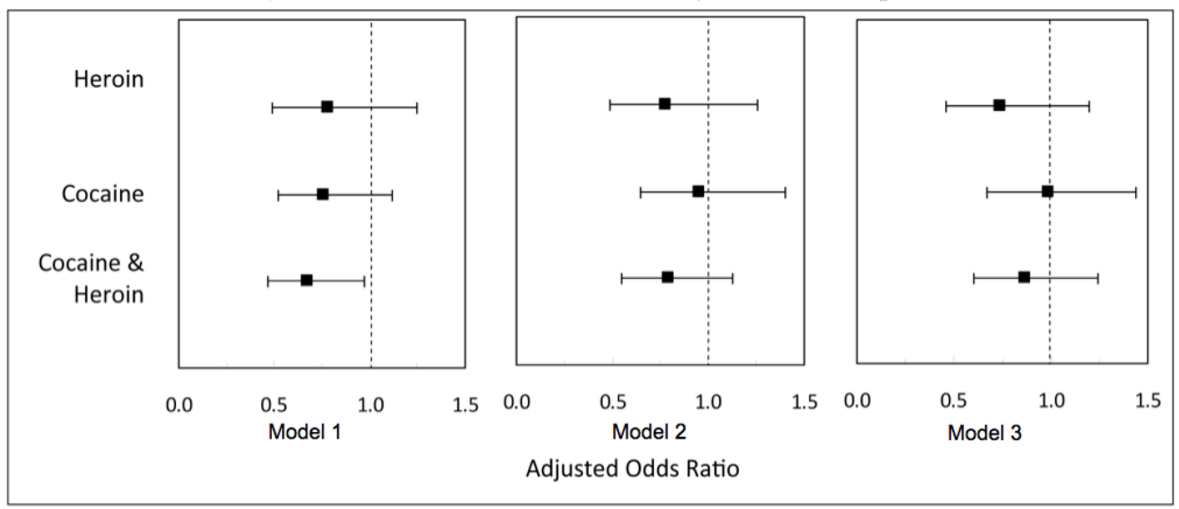

Figure 2.

The relationship between substance use throughout follow-up and time to viral load suppression among a prospective cohort of HIV-positive injection drug users $(n=267)$. Model 1: Unadjusted association between drug use and viral load suppression. Model 2: Adjusted for baseline CD4 count, baseline $\log _{10}$ (viral load). Model 3: Adjusted for baseline CD4 count, baseline $\log _{10}$ (viral load), age, current enrollment in methadone maintenance therapy, adherence (past 6 months), and ART regimen. 


\section{Table 1}

Baseline characteristics of HIV-positive drug users stratified by injecting versus non-injecting drug use ( $\mathrm{n}=$ 267)

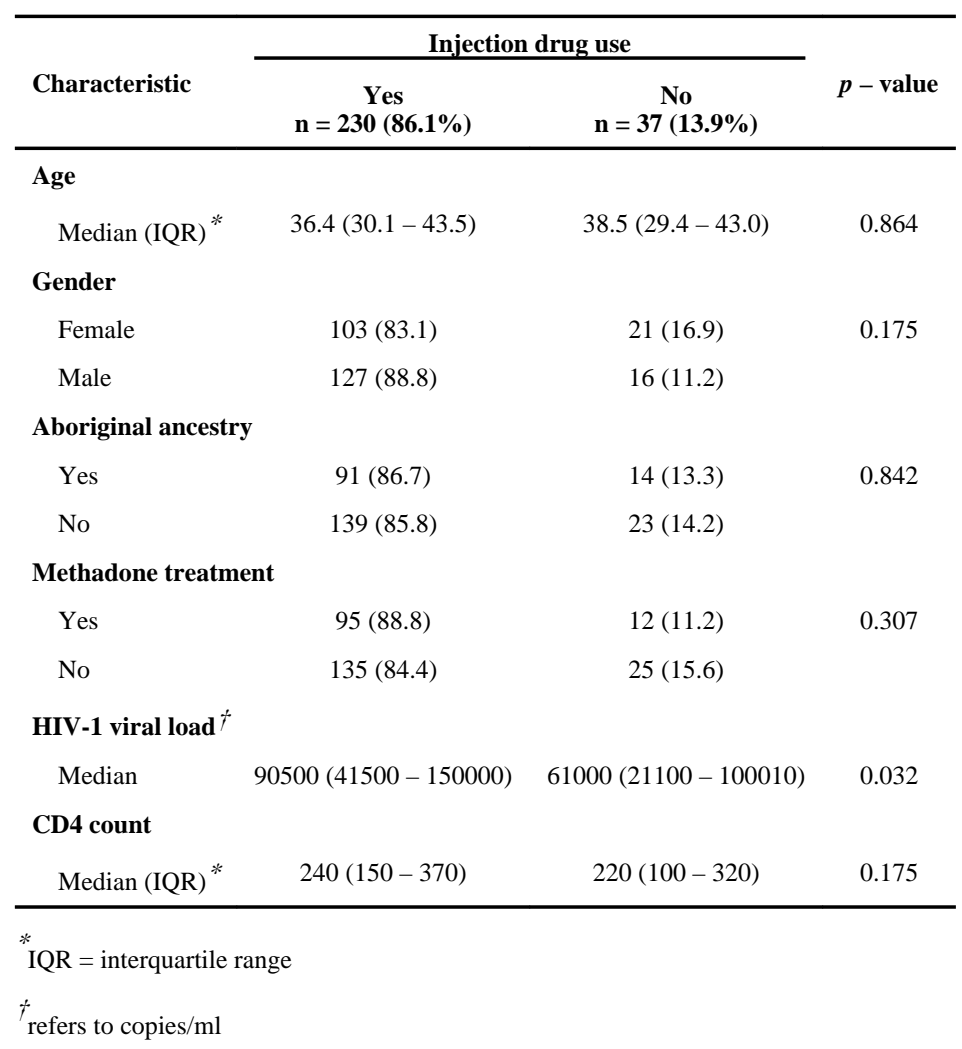

